\title{
Use of in vitro tests to assess the causative drugs for NSAIDs-induced type I hypersensitivity
}

\author{
Wan-Chun Chang ${ }^{1 *}$, Bi-Kai Hsu', Wen-Hung Chung ${ }^{2}$, Shuen-lu Hung ${ }^{1}$ \\ From 6th Drug Hypersensitivity Meeting (DHM 6) \\ Bern, Switzerland. 9-12 April 2014
}

Non-steroidal anti-inflammatory drugs (NSAIDs) are associated with type I hypersensitivity, including cutaneous manifestations (e.g., urticaria and angioedema), respiratory manifestations (rhinitis, nasal polyposis, asthma), and anaphylaxis. To assess the sensitivity/specificity of in vitro tests for verifying the causative/tolerant drugs and crossreactivity of different NSAIDs, we used three assays, including two ELISA tests for histamine/leukotriene C4 (LTC4) release, and a flow cytometric basophil activation test (BAT). We recruited 82 patients with NSAIDsinduced type I hypersensitivity (angioedema of the most cases), and isolated the peripheral leukocytes to perform histamine/LTC4 release tests in 38 patients, and BAT in 44 patients. The cell response to NSAIDs was examined in the incubation containing suspected or tolerant drugs with concentrations equal to 1 -fold (physical level) or 10-fold Cmax. Comparing with the data of solve controls of the same subject, positive response was considered if the histamine/LTC4 release showed 1.2-fold increase, and BAT detected more than $5 \%$ increase of CD63+/CCR3+ cells. We found that histamine release test had a sensitivity of $41.9 \%(26 / 62)$, and specificity of $100 \%$ (10/10).LTC4 release test had a sensitivity of $32.3 \%$ (20/62), and specificity of $90 \%(9 / 10)$. BAT had a sensitivity of $46.4 \%(39 / 84)$ and specificity of $90 \%(18 / 20)$ for NSAIDs-induced type I hypersensitivity. Regarding drug classification, the four most common clinically suspected agents were aspirin, ibuprofen, diclofenac, and acetaminophen. The three assays have consistently $>50 \%$ sensitivity for verifying aspirin, but various sensitivity and diverse individual response for the other NSAIDs. Heterogeneous mechanisms including both immunology and pharmacology may be involved in NSAIDs-induced type I hypersensitivity.

${ }^{1}$ National Yang-Ming University, Institution of Pharmacology, Taiwan Full list of author information is available at the end of the article

\section{Authors' details}

${ }^{1}$ National Yang-Ming University, Institution of Pharmacology, Taiwan.

${ }^{2}$ Chang Gung Memorial Hospital, Department of Dermatology, Taiwan.

Published: 18 July 2014

doi:10.1186/2045-7022-4-S3-P31

Cite this article as: Chang et al.: Use of in vitro tests to assess the

causative drugs for NSAIDs-induced type I hypersensitivity. Clinical and Translational Allergy 2014 4(Suppl 3):P31.
Submit your next manuscript to BioMed Central and take full advantage of:

- Convenient online submission

- Thorough peer review

- No space constraints or color figure charges

- Immediate publication on acceptance

- Inclusion in PubMed, CAS, Scopus and Google Scholar

- Research which is freely available for redistribution
() Biomed Central

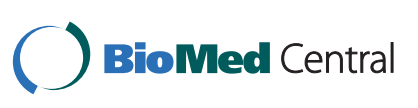

